Arq. Bras. Med. Vet. Zootec., v.66, n.6, p.1822-1830, 2014

\title{
Degradabilidade ruminal in situ do sorgo grão em diferentes formas de reconstituição
}

\author{
[In situ ruminal degradability of sorghum grain in different \\ forms of reconstruction] \\ J.S. Silva ${ }^{1,5}$, A.L.C.C. Borges $^{2}$, F.C.F. Lopes $^{3}$, R.R. Silva ${ }^{2}$, A.R. Vieira ${ }^{2}$, A.C.A. Duque ${ }^{2}$, \\ I. Borges ${ }^{2}$, J.A.S. Rodrigues ${ }^{4}$, L.C. Gonçalves ${ }^{2}$ \\ ${ }^{1}$ Aluna de pós-graduação - Escola de Veterinária - UFMG - Belo Horizonte, MG \\ ${ }^{2}$ Escola de Veterinária - UFMG - Belo Horizonte, MG \\ ${ }^{3}$ Embrapa Gado de Leite - Juiz de Fora, MG \\ ${ }^{4}$ Embrapa Milho e Sorgo - Sete Lagoas, MG \\ ${ }^{5}$ Bolsista da CAPES
}

\begin{abstract}
RESUMO
Foram utilizadas três vacas não lactantes fistuladas no rúmen com o objetivo de determinar os parâmetros de degradação ruminal in situ da matéria seca (MS) e do amido de grãos de sorgo sob diferentes formas de processamento: 1) Seco e moído (2mm); 2) Seco, moído (3mm), reidratado com aspersão de água sobre o material, e imediatamente ensilado por 30 dias; 3) Seco, inteiro, reidratado por três dias em tubo PVC e, em seguida, moído a 5mm; 4) Seco, inteiro, reidratado por três dias em tubo PVC com aplicação de ar comprimido e, em seguida, moído a 5mm; 5) Seco, inteiro, reidratado por três dias em tubo PVC e, em seguida, moído a 5mm, e ensilado por 30 dias; 6) Seco, inteiro, reidratado por três dias em tubo PVC com aplicação de ar comprimido, moído a 5mm e ensilado por 30 dias. Os teores de proteína bruta, amido, e fibra em detergente neutro (\% da MS) variaram de 9,8 a 10,8\%; 59,5 a 67,5\%; e de 16,1 a $19,3 \%$, respectivamente. Os teores de umidade nos grãos que foram reidratados variaram de 35,8 a 43,9\% da MS. A taxa e a extensão de degradação do amido e a degradabilidade potencial da MS foram semelhantes $(\mathrm{P}>0,05)$ entre tratamentos. Os grãos de sorgo reidratados com aplicação de ar comprimido, moídos e ensilados (tratamento 6) apresentaram degradabilidade efetiva (DE) da MS e DE do amido sob taxa de passagem ruminal de $2 \% / \mathrm{h}$, semelhantes $(\mathrm{P}>0,05)$ às observadas para o tratamento 5 (sem aplicação de ar comprimido), e superiores $(\mathrm{P}<0,05)$ às dos demais processamentos. Sob taxas de passagem no rúmen de 5 e $8 \% / \mathrm{h}$, as $\mathrm{DE}$ do amido estimadas para os grãos processados no tratamento 6 foram superiores $(\mathrm{P}<0,05)$ às obtidas para os demais tratamentos. $\mathrm{O}$ processamento de reidratação por três dias com aplicação de ar comprimido e ensilagem por trinta dias aumentou a degradabilidade efetiva da matéria seca e do amido dos grãos de sorgo, e sua utilização pode ser recomendada para animais em níveis intermediário e elevado de desempenho.
\end{abstract}

Palavras-chave: amido, ensilagem, processamento, reidratação

\begin{abstract}
Used three non-lactating cows fistulated in the rumen in order to determine the parameters of in situ ruminal degradation of dry matter (DM) and starch grain sorghum under different forms of processing: 1) Dried and ground (2mm); 2) Dry, crushed (3mm), rehydrated with water spray on the material and immediately ensiled for 30 days, 3) Dry, round, rehydrated for three days in PVC pipe and then crushed to 5mm, 4 ) Dry, full-rehydrated for three days in PVC tube with application of compressed air and then ground to 5mm; 5) Dry, full-rehydrated for three days in PVC pipe and then ground to 5mm, and ensiled for 30 days; 6) Dry, full-rehydrated for three days in PVC tube with application of compressed air, ground to $5 \mathrm{~mm}$ and ensiled for 30 days. The crude protein, starch, and neutral detergent fiber (\% of DM) ranged
\end{abstract}

Recebido em 4 de abril de 2013

Aceito em 10 de junho de 2014

E-mail: julamim@yahoo.com.br 
from 9.8 to $10.8 \%, 59.5$ to $67.5 \%$, and 16.1 to $19.3 \%$, respectively. The moisture in the grains that were rehydrated ranged from 35.8 to $43.9 \%$ DM. The rate and extent of starch degradation and the degradability of $M S$ were similar $(P>0.05)$ between treatments. The grain sorghum rehydrated with application of compressed air, ground and ensiled (treatment 6), showed effective degradability (ED) of $D M$, and DE starch under ruminal passage rate of $2 \% / h$, similar $(P>0.05)$ those observed for treating 5 (without application of compressed air) and higher $(P<0.05)$ to the other processing. Under rumen passage rates of 5 and $8 \% / h$, the estimated NDs starch for processed grains in treatment 6 were higher $(P<0.05)$ than those obtained for the other treatments. Processing rehydration for three days with compressed air application and silage for thirty days increased the effective degradability of dry matter and starch grain sorghum, and its use can be recommended for animals in intermediate and high performance.

Keywords: starch, silage, processing, rehydration

\section{INTRODUÇÃO}

O sorgo possui valor nutritivo semelhante ao do milho em dietas de ruminantes, sem causar alterações no metabolismo do animal ou no desempenho produtivo, e ainda pode proporcionar ganhos em termos econômicos, sendo que a sua utilização dependerá da oferta e do preço (Faria Jr. et al., 2009).

Devido às características físicas do grão (tamanho, resistência à degradação etc.), o milho e o sorgo apresentam maiores benefícios quando processados, pois, nesses grãos, encontra-se uma matriz proteica que dificulta o ataque enzimático. $\mathrm{O}$ processo de moagem e reconstituição, para a alimentação de ruminantes, visa aumentar a área superficial para facilitar os processos digestivos, sejam eles fermentativos ou enzimáticos, melhorando o desempenho animal (Pereira et al., 2011).

A reconstituição é um processo que envolve a mistura do grão com água para alcançar teor de umidade de, no mínimo, 30\%, seguido do armazenamento dos grãos úmidos sob condições limitantes de oxigênio, entre 14 e 21 dias. O grão úmido absorve o oxigênio da água, bem como da atmosfera, resultando no início da germinação, um processo que envolve a hidrólise de proteínas e carboidratos no endosperma dos grãos (Balogun et al., 2005). Conforme Jobim et al. (2003) descreveram, os ácidos orgânicos produzidos durante o processo podem causar rupturas na matriz proteica que recobre os grânulos de amido, bem como na estrutura desses grânulos, favorecendo a digestão e absorção do amido.
A reconstituição de grãos vem sendo utilizada como alternativa para garantir a manutenção da qualidade nutricional da safra nas propriedades rurais, em função das dificuldades de armazenagem do grão seco.

São citadas na literatura diferentes formas de reconstituição de grãos de sorgo. Os procedimentos de reconstituição variam, principalmente, quanto à quantidade de água $\mathrm{e}$ oxigênio adicionados, e ao estado físico do grão na mistura (inteiro ou moído).

A degradabilidade ruminal in situ é uma técnica comumente utilizada em pesquisa de nutrição de ruminantes, notadamente fornecendo informações relacionadas às taxas e extensões de degradação das frações componentes dos alimentos volumosos e concentrados.

Objetivou-se avaliar os efeitos de diferentes procedimentos de reconstituição do grão de sorgo sobre a degradabilidade ruminal in situ da matéria seca e do amido.

\section{MATERIAL E MÉTODOS}

Utilizou-se o grão de sorgo híbrido BRS 310, safra 2010/2011, oriundo da Embrapa Milho e Sorgo, localizada em Sete Lagoas, Minas Gerais.

Realizou-se um teste para determinar a energia germinativa (uma medida da taxa de germinação) do grão de sorgo com base no trabalho desenvolvido por Balogun et al. (1995): dez grãos foram selecionados aleatoriamente $\mathrm{e}$ umedecidos com $3 \mathrm{~mL}$ de água, colocados em condições normais de ambiente, sem luz solar direta, por três dias. 
Foram utilizados para reconstituição quatro tubos de PVC, com 200mm de diâmetro e $1 \mathrm{~m}$ de altura. Cada recipiente foi numerado, conforme os tratamentos 3, 4, 5 e 6, descritos na Tab. 1 . Nos tratamentos 4 e 6 , foi estabelecida aerobiose utilizando compressor de ar atmosférico de pressão e fluxo constantes (modelo Seven Star Power 500 - 5W, São Paulo, SP), colocado logo acima da base do tubo de PVC.

Tabela 1. Descrição dos tratamentos experimentais

\begin{tabular}{|c|c|}
\hline Tratamentos & Descrição dos processamentos \\
\hline 1 & Grão de sorgo seco e moído ( $2 \mathrm{~mm})$ \\
\hline 2 & $\begin{array}{l}\text { Grão de sorgo seco, moído }(3 \mathrm{~mm}) \text {, reidratado com aspersão de água sobre o material } \\
\text { que foi imediatamente ensilado por } 30 \text { dias }\end{array}$ \\
\hline 3 & $\begin{array}{l}\text { Grão de sorgo seco, inteiro, reidratado por três dias em tubo PVC e, em seguida, } \\
\text { moído a } 5 \mathrm{~mm}\end{array}$ \\
\hline 4 & $\begin{array}{l}\text { Grão de sorgo seco, inteiro, reidratado por três dias em tubo PVC com aplicação de } \\
\text { ar comprimido e, em seguida, moído a } 5 \mathrm{~mm}\end{array}$ \\
\hline 5 & $\begin{array}{l}\text { Grão de sorgo seco, inteiro, reidratado por três dias em tubo PVC e, em seguida, } \\
\text { moído a } 5 \mathrm{~mm} \text {, e imediatamente ensilado por } 30 \text { dias }\end{array}$ \\
\hline 6 & $\begin{array}{l}\text { Grão de sorgo seco, inteiro, reidratado por três dias em tubo PVC com aplicação de } \\
\text { ar comprimido, moído a } 5 \mathrm{~mm} \text { e, imediatamente, ensilado por } 30 \text { dias }\end{array}$ \\
\hline
\end{tabular}

Os procedimentos de reidratação foram realizados em local fechado, protegido de vento e com baixa luminosidade (Laboratório de Calorimetria e Respirometria Animal da Escola de Veterinária da UFMG, Belo Horizonte, MG) no período de 8 a 11 de junho de 2011 , com temperatura ambiente variando de 13 a $28^{\circ} \mathrm{C}$.

No tratamento 1, o grão de sorgo seco foi apenas moído a $2 \mathrm{~mm}$ em moinho estacionário "ThomasWiley", modelo 4 (São Paulo, SP). O grão de sorgo seco utilizado no tratamento 2 foi moído a $3 \mathrm{~mm}$, utilizando o mesmo moinho. Logo após, aspergiu-se água sobre o sorgo, misturou-se e ensilou-se o material. Nos tratamentos 3, 4, 5 e 6 foram colocados dentro dos tubos de PVC água e grãos de sorgo. Nos tratamentos 4 e 6, adicionalmente, foi feita aplicação de ar comprimido sob fluxo constante (Tab. 1). Considerou-se a altura de $70 \mathrm{~cm}$ de sorgo nos tubos de PVC, conforme procedimento relatado por Vieira (2011). A quantidade de água adicionada para atingir a umidade final desejada (35\%) foi estimada a partir da Equação 1, de Ferreira (1983), adaptada por Lopes et al. (2005).

Após três dias de reidratação, retirou-se toda a água dos tubos de PVC e, em seguida, os grãos úmidos dos tratamentos $3,4,5$ e 6 (Tab. 1) foram moídos a 5mm, no mesmo moinho relatado anteriormente. Os materiais oriundos dos tratamentos 3 e 4 foram colocados em estufa de circulação forçada de ar, regulada para $55^{\circ} \mathrm{C}$ por 72 h. Os grãos de sorgo reconstituídos dos tratamentos 5 e 6, após moídos a $5 \mathrm{~mm}$, bem como o material final referente ao tratamento 2 , foram ensilados em triplicata em silos experimentais de PVC (400mm x 100mm) dotados de válvula do tipo Bunsen. Os silos cheios foram previamente pesados, prensados, lacrados e armazenados. Os silos foram abertos 30 dias após a ensilagem do material, mesmo tempo utilizado por Vieira (2011). Posteriormente, amostras de cada silo foram présecadas em estufa de ventilação forçada a $55^{\circ} \mathrm{C}$, por três dias.

$\mathrm{O}$ ensaio de digestibilidade in situ foi realizado em setembro de 2011 no Campo Experimental José Henrique Bruschi, da Embrapa Gado de Leite, localizado em Coronel Pacheco (MG). O experimento foi realizado sob aprovação do Comitê de Ética em Experimentação Animal da Universidade Federal de Minas Gerais (Protocolo CETEA no 214/10). Utilizaram-se três vacas Holandês x Gir não lactantes, fistuladas no rúmen e dotadas de cânulas de borracha natural, com 110mm de diâmetro interno de abertura (Kehl Ind. Com. Ltda., São Carlos, SP), pesando, em média, $529,55 \pm 40,15 \mathrm{~kg}$. 
A dieta utilizada para a alimentação das vacas foi fornecida ad libitum $(10 \%$ de sobras $)$ e continha, com base na matéria seca (MS), $80 \%$ de silagem de milho e $20 \%$ de concentrado, dos quais $14 \%$ foram de sorgo grão moído (BRS 310 ), $5 \%$ de farelo de soja e $1 \%$ de mistura mineral. A dieta apresentou, em média, 9,9\% de proteína bruta $(\mathrm{PB}), 5,5 \%$ de matéria mineral (MM) e $61,7 \%$ de fibra em detergente neutro (FDN) na base da MS. As vacas foram alojadas em curral do tipo free-stall, dispondo de bebedouro comum, de cochos com portões eletrônicos do tipo calan-gate (American Calan Inc., Northewwod, EUA) e cama de areia. O período de adaptação à dieta foi de 14 dias e o de incubação, de quatro dias.

Para incubação no rúmen das vacas, pesaram-se $5 \mathrm{~g}$ de amostra previamente moída a $2 \mathrm{~mm}$ de cada tratamento (Tab. 1), que foram colocados nos sacos de náilon $(10 \times 20 \mathrm{~cm}$ de dimensão; porosidade de $50 \mu ; 10$ a $20 \mathrm{mg}$ de amostra $/ \mathrm{cm}^{2}$ de área de saco) devidamente identificados. Os tempos de incubação adotados foram $0,2,4,6$, $12,24,48$ e 72 horas. Utilizou-se um saco de náilon para o tempo 0 ; dois, para os tempos 2, 4 e 6 h de incubação; e três, para os demais. Após a pesagem, os sacos foram colocados em correntes, mergulhados em água (temperatura ambiente, 30 min) e incubados no rúmen das vacas, imediatamente antes do fornecimento da dieta. Incubaram-se 108 sacos em cada vaca. Nos respectivos tempos de 2, 4, 6, 12, 24, 48 e 72 horas de incubação, os sacos eram retirados do rúmen, mergulhados em balde com água à temperatura ambiente para limpeza inicial e cessar a degradação e, em seguida, congelados.

Os sacos correspondentes ao tempo zero foram mergulhados em água destilada a $40^{\circ} \mathrm{C}$, em banho-maria, por $30 \mathrm{~min}$. Em seguida, foram lavados em água corrente e congelados com os demais. Após 24 horas de congelamento, todos os sacos foram lavados em conjunto até o clareamento da água. Os mesmos foram colocados em estufa de ventilação forçada $\left(55^{\circ} \mathrm{C}\right.$, $72 \mathrm{~h}$ ), e, posteriormente, anotaram-se os pesos dos sacos contendo os resíduos de incubação, que foram analisados no Laboratório de Análise de Alimentos da Embrapa Gado de Leite (Juiz de Fora, MG) quanto aos teores de $\mathrm{MS}$ a $105^{\circ} \mathrm{C}$ (Silva e Queiroz, 2002) e de amido. Para determinação da concentração de amido, inicialmente, procedeu-se à hidrólise ácida com ácido clorídrico 0,6 M (Passos, 1996). Posteriormente, usou-se o kit PAP Liquiform ref. 84 (Labtest Diagnostica S.A., Lagoa Santa, MG) para reagir com a glicose livre e formar uma solução de cor vermelha. A leitura foi feita em espectrofotômetro (UV-380G, marca Gehaka, São Paulo, SP) com luz de tungstênio. A concentração de glicose foi multiplicada por 0,9 para se obter a concentração de amido na amostra.

Os parâmetros de degradação ruminal da MS e amido foram estimados pelo processo iterativo do algoritmo Marquardt, com auxílio do procedimento para modelos não lineares (PROC NLIN) do SAS (Statistical..., 2002), utilizando a equação descrita por Sampaio et al. (1995). Os tempos de colonização (lag-time) foram calculados conforme relatado por Lopes et al. (2008), e as degradabilidades efetivas (DE), segundo Ørskov e McDonald (1979), utilizandose taxas de passagem no rúmen de 2,5 e $8 \% / \mathrm{h}$ (The Nutrient..., 1984).

A análise de variância dos parâmetros de degradação ruminal da MS e amido foi realizada utilizando-se o procedimento GLM do SAS (Statistical..., 2002), considerando-se os efeitos de bloco (vaca) e tratamento. Para comparação das médias $(\alpha=0,05)$ utilizou-se o teste de Bonferroni.

\section{RESULTADOS E DISCUSSÃO}

Os grãos de sorgo apresentaram $70 \%$ de energia germinativa. $\mathrm{O}$ conhecimento do percentual de germinação é fundamental, pois indica a quebra da dormência da semente. No estudo de Balogun et al. (1995), 40\% dos grãos germinaram, e os autores consideraram baixa a energia germinativa dos grãos utilizados.

Após o processamento de três dias de reidratação, consideraram-se grãos germinados aqueles que apresentaram radícula emergente, sendo expressos como porcentagem em relação ao total. Os tratamentos 3 e 5, que não utilizaram aplicação de ar comprimido (Tab. 1), não demonstraram radícula na semente.

O teor inicial de MS dos grãos de sorgo foi $87,0 \%$. Os grãos que foram moídos secos, reidratados por aspersão e ensilados imediatamente (tratamento 2) atingiram 40,3\% 
de umidade (Tab. 2). Os teores de umidade do sorgo em que os grãos inteiros foram apenas reidratados (tratamento 3) e daqueles que, durante a reidratação tiveram aplicação de ar comprimido (tratamento 4), foram, respectivamente, de $39,4 \%$ e $43,9 \%$ de umidade. Os grãos que foram reidratados inteiros, moídos e ensilados (tratamentos 5 e 6 ) atingiram $35,9 \%$ e $39,4 \%$ de umidade, respectivamente, após a ensilagem (Tab. 2).

Tabela 2. Composição bromatológica dos grãos processados, em porcentagem da matéria seca (MS)

\begin{tabular}{ccccccccc}
\hline & $\begin{array}{c}\text { MS } \\
\text { Tratamento* }\end{array}$ & $\begin{array}{c}\text { Proteína } \\
\text { bruta }\end{array}$ & Amido & Cinzas & $\begin{array}{c}\text { FDN - Fibra em } \\
\text { detergente } \\
\text { neutro }\end{array}$ & $\begin{array}{c}\text { FDA - Fibra em } \\
\text { detergente } \\
\text { ácido }\end{array}$ & FDNcp $^{1}$ & FDAcp $^{2}$ \\
\hline 1 & 86,97 & 10,49 & 61,07 & 1,63 & 18,15 & 6,35 & 11,58 & 1,60 \\
2 & 59,74 & 9,80 & 64,45 & 1,53 & 18,43 & 6,05 & 11,96 & 2,21 \\
3 & 60,63 & 10,69 & 67,55 & 1,42 & 19,33 & 6,38 & 12,35 & 1,90 \\
4 & 56,11 & 10,55 & 63,51 & 1,88 & 17,91 & 7,28 & 13,34 & 2,65 \\
5 & 64,22 & 10,81 & 59,55 & 1,37 & 16,26 & 5,23 & 10,14 & 1,86 \\
6 & 60,57 & 9,84 & 64,30 & 1,08 & 16,11 & 4,09 & 10,84 & 1,14 \\
\hline
\end{tabular}

*1) Grão de sorgo seco e moído (2mm); 2) Grão de sorgo seco, moído (3mm), reidratado com aspersão de água sobre o material, que foi imediatamente ensilado por 30 dias; 3) Grão de sorgo seco, inteiro, reidratado por três dias em tubo PVC e, em seguida, moído a 5mm; 4) Grão de sorgo seco, inteiro, reidratado por três dias em tubo PVC com aplicação de ar comprimido e, em seguida, moído a $5 \mathrm{~mm}$; 5) Grão de sorgo seco, inteiro, reidratado por três dias em tubo PVC e, em seguida, moído a 5mm, e imediatamente ensilado por 30 dias; 6) Grão de sorgo seco, inteiro, reidratado por três dias em tubo PVC com aplicação de ar comprimido, moído a $5 \mathrm{~mm}$ e, imediatamente, ensilado por 30 dias.

${ }^{1} \mathrm{FDNcp}=$ FDN corrigido para cinzas e proteínas; ${ }^{2} \mathrm{FDAcp}=$ FDA corrigido para cinzas e proteínas.

Os teores de amido variaram entre $59,55 \%$ para o tratamento 5, e $67,55 \%$ para o tratamento 3 (Tab. 2). Ambos os tratamentos foram reidratados por três dias sem aplicação de ar comprimido, e não apresentaram germinação, porém o tratamento 5 foi, adicionalmente, ensilado por 30 dias. Vieira (2011) observou que o percentual de amido encontrado nos grãos de sorgo após a reconstituição $(57,42 \%)$ foi menor que nos grãos secos $(65,44 \%)$. O teor de PB dos grãos de sorgo que foram somente secos e moídos foi $10,49 \%$ (Tab. 2). Após os processamentos, o menor valor $(9,80 \%)$ foi encontrado para os grãos de sorgo secos moídos, reidratados e ensilados (tratamento 2), que foi próximo aos valores dos grãos de sorgo inteiros, reidratados com aplicação de ar comprimido e ensilados (tratamento 6) (Tab. 2).

Segundo Sampaio et al. (1995), a degradabilidade potencial ("A") e a taxa de degradação ("c") são importantes parâmetros de degradação ruminal a serem considerados na qualificação nutricional de forrageiras. Verificou- se que os valores de degradabilidade potencial da MS foram semelhantes $(\mathrm{P}>0,05)$ para todos os tratamentos (Tab. 3). O valor da taxa de degradação da MS observado para o tratamento 6 (grãos de sorgo inteiros reidratados com aplicação de ar comprimido e ensilados) foi superior $(\mathrm{P}<0,05)$ àqueles estimados para os tratamentos 1, 3 e 4, que utilizaram grãos moídos, ou reidratados, ou reidratados com aplicação de ar, respectivamente. Por sua vez, a taxa de degradação da MS observada no tratamento 6 foi semelhante às dos tratamentos 2 e 5, que foram reidratados e ensilados (Tab. 3). Os grãos de sorgo que foram ensilados (tratamentos 2, 5 e 6) apresentaram os maiores valores de fração solúvel ("S") da MS (Tab. 3). Balogun et al. (2005) encontraram para o tempo zero de incubação, que representa a fração solúvel em água, valores significativamente maiores para os tratamentos com grãos de sorgo germinados por cinco dias, e para grãos de sorgo germinados por cinco dias e ensilados por 16 dias. 
Degradabilidade ruminal...

Tabela 3. Parâmetros de degradação ruminal in situ da matéria seca de grãos de sorgo submetidos a diferentes formas de processamento

\begin{tabular}{cccccccccc} 
& \multicolumn{10}{c}{ Parâmetro de degradação $^{2}$} \\
\cline { 2 - 10 } Tratamento $^{1}$ & $\begin{array}{c}\mathrm{A} \\
(\%)\end{array}$ & $\begin{array}{c}\mathrm{B} \\
(\%)\end{array}$ & $\begin{array}{c}\mathrm{c} \\
(\% / \mathrm{h})\end{array}$ & $\begin{array}{c}\text { LAG } \\
(\mathrm{h})\end{array}$ & $\begin{array}{c}\mathrm{S} \\
(\%)^{3}\end{array}$ & $\begin{array}{c}\text { B1 } \\
(\%)\end{array}$ & $\begin{array}{c}\text { DE2 } \\
(\%)\end{array}$ & $\begin{array}{c}\text { DE5 } \\
(\%)\end{array}$ & $\begin{array}{c}\text { DE8 } \\
(\%)\end{array}$ \\
\hline 1 & 94,8 & $85,8 \mathrm{a}^{4}$ & $3,1 \mathrm{~b}$ & $3,4 \mathrm{a}$ & 17,8 & $77,0 \mathrm{ab}$ & $64,7 \mathrm{c}$ & $47,4 \mathrm{c}$ & $39,4 \mathrm{c}$ \\
2 & 93,7 & $81,7 \mathrm{ab}$ & $3,8 \mathrm{ab}$ & $2,6 \mathrm{a}$ & 20,1 & $73,6 \mathrm{~b}$ & $68,2 \mathrm{~b}$ & $51,9 \mathrm{~b}$ & $43,8 \mathrm{~b}$ \\
3 & 93,7 & $84,1 \mathrm{a}$ & $3,2 \mathrm{~b}$ & $1,6 \mathrm{ab}$ & 14,6 & $79,0 \mathrm{a}$ & $63,2 \mathrm{c}$ & $46 \mathrm{c}$ & $37,7 \mathrm{c}$ \\
4 & 92,8 & $73,1 \mathrm{~b}$ & $3,3 \mathrm{~b}$ & $0,0 \mathrm{~b}$ & 16,8 & $76,1 \mathrm{ab}$ & $64,4 \mathrm{c}$ & $47,3 \mathrm{c}$ & $39,3 \mathrm{c}$ \\
5 & 95,2 & $74,5 \mathrm{~b}$ & $3,6 \mathrm{ab}$ & $1,3 \mathrm{ab}$ & 24,5 & $70,7 \mathrm{c}$ & $69,8 \mathrm{ab}$ & $54,0 \mathrm{ab}$ & $46,4 \mathrm{ab}$ \\
6 & 95,3 & $74,9 \mathrm{~b}$ & $4,1 \mathrm{a}$ & $0,6 \mathrm{ab}$ & 23,7 & $71,7 \mathrm{c}$ & $72,0 \mathrm{a}$ & $56,2 \mathrm{a}$ & $48,2 \mathrm{a}$ \\
\hline EPM $^{5}$ & 0,69 & 1,67 & 0,15 & 0,55 & - & 0,69 & 0,59 & 0,60 & 0,54
\end{tabular}

${ }^{1}$ 1) Grão de sorgo seco e moído (2mm); 2) Grão de sorgo seco, moído (3mm), reidratado com aspersão de água sobre o material, que foi imediatamente ensilado por 30 dias; 3) Grão de sorgo seco, inteiro, reidratado por três dias em tubo PVC e, em seguida, moído a 5mm; 4) Grão de sorgo seco, inteiro, reidratado por três dias em tubo PVC com aplicação de ar comprimido e, em seguida, moído a $5 \mathrm{~mm}$; 5) Grão de sorgo seco, inteiro, reidratado por três dias em tubo PVC e, em seguida, moído a 5mm, e imediatamente ensilado por 30 dias; 6) Grão de sorgo seco, inteiro, reidratado por três dias em tubo PVC com aplicação de ar comprimido, moído a $5 \mathrm{~mm}$ e, imediatamente, ensilado por 30 dias;

${ }^{2} \mathrm{~A}$ = fração potencialmente degradável; $\mathrm{B}$ = fração potencialmente degradável sob ação da microbiota, se não houvesse tempo de colonização (LAG); $c$ = taxa constante de degradação da fração potencialmente degradável por ação da microbiota; $\mathrm{S}=$ fração solúvel + partículas com tamanho reduzido que atravessam os poros do náilon; $\mathrm{B} 1=$ fração potencialmente degradável sob ação da microbiota (A-S); DE2, DE5 e DE8 = degradabilidades efetivas calculadas, considerando-se taxas de passagem no rúmen $(\mathrm{k} 1)$ de $2 ; 5 \mathrm{e} 8 \% / \mathrm{h}$, respectivamente $(\mathrm{DE}=\mathrm{S}+((\mathrm{B} 1 * \mathrm{c}) /(\mathrm{c}$ $+\mathrm{k} 1))$ );

${ }^{3}$ Não foi feita análise de variância. $\mathrm{O}$ dado apresentado refere-se ao valor médio de três réplicas;

${ }^{4}$ Letras distintas na mesma coluna indicam médias diferentes $(\mathrm{P}<0,05)$;

${ }^{5} \mathrm{EPM}=$ Erro padrão da média.

O processamento realizado no tratamento 5 (reidratação e ensilagem dos grãos) foi semelhante ao utilizado por Vieira (2011), que estudou o efeito da reconstituição do grão de sorgo na dieta de novilhos Nelore confinados. Segundo o autor, a digestibilidade aparente e o consumo de MS dos novilhos não foram alterados $(\mathrm{P}>0,05)$ com a reidratação e a ensilagem do sorgo. No presente trabalho, verificou-se que os procedimentos de reidratação e ensilagem aplicados aos grãos de sorgo do tratamento 5 permitiram incremento $(\mathrm{P}<0,05)$ na degradabilidade ruminal da MS quando comparada com a observada nos grãos do tratamento 1, que foram apenas moídos (Tab. 3).

Andrade Filho et al. (2010) avaliaram os efeitos da reconstituição e da ensilagem na degradabilidade ruminal efetiva da MS de grãos de milho com texturas dentado e flint. Houve interação entre tipo de híbrido e ensilagem $(\mathrm{P}<0,05)$. A ensilagem aumentou $(\mathrm{P}<0,001)$ a degradabilidade ruminal efetiva da MS em $23,2 \%$ e $42,4 \%$ na comparação com os grãos secos do tipo dentado e flint, respectivamente. Segundo os autores, a técnica de reconstituição e ensilagem pode aumentar a degradabilidade e o valor nutritivo dos grãos maduros de milho dos tipos dentado e flint.

Os maiores valores de DE da MS foram obtidos para o tratamento 6 , em que os grãos de sorgo foram reidratados com aplicação de ar comprimido e ensilados (Tab. 3). Isso pode ser parcialmente explicado pelas elevadas taxas de degradação e pelo teor da fração solúvel " $S$ " da 
MS (Tab. 3). Conforme já discutido para o tratamento 5, também estes resultados mostram a importância da reidratação e da ensilagem dos grãos de sorgo no incremento de seu valor nutricional. Convém destacar que o tratamento 2, em que os grãos foram moídos secos, reidratados por aspersão e ensilados, apresentou incremento $(\mathrm{P}<0,05)$ na $\mathrm{DE}$ da MS desses grãos (Tab. 3) quando comparados com aqueles que foram apenas moídos (Tratamento 1), indicando o potencial desses procedimentos em aumentar o valor nutricional dos grãos.

Não houve efeito $(\mathrm{P}>0,05)$ dos tratamentos sobre a degradabilidade potencial (“A”) do amido. Da mesma forma, os diferentes processamentos do grão de sorgo avaliados no presente trabalho não alteraram $(\mathrm{P}>0,05)$ a taxa de degradação ("c") do amido nem o tempo de colonização "LAG" (Tab. 4). O tratamento 6, em que grãos de sorgo foram reidratados com aplicação de ar comprimido e ensilados, apresentou a maior fração solúvel ("S") dentre todos os procedimentos. Isso ocorreu, provavelmente, porque o rompimento da estrutura cristalina dos grânulos de amido aumentou a sua solubilidade, tornando-os mais acessíveis à degradação, conforme descrito por Nocek (1988)

Tabela 4. Parâmetros de degradação ruminal in situ do amido de grãos de sorgo submetidos a diferentes formas de processamento

\begin{tabular}{|c|c|c|c|c|c|c|c|c|c|}
\hline \multirow{2}{*}{ Tratamento $^{1}$} & \multicolumn{9}{|c|}{ Parâmetro de degradação ${ }^{2}$} \\
\hline & $\begin{array}{c}\text { A } \\
(\%)\end{array}$ & $\begin{array}{c}\mathrm{B} \\
(\%)\end{array}$ & $\begin{array}{c}\mathrm{c} \\
(\% / \mathrm{h})\end{array}$ & $\begin{array}{c}\text { LAG } \\
\text { (h) }\end{array}$ & $\begin{array}{c}\mathrm{S} \\
(\%)^{3}\end{array}$ & $\begin{array}{l}\text { B } 1 \\
(\%)\end{array}$ & $\begin{array}{c}\text { DE2 } \\
(\%)\end{array}$ & $\begin{array}{l}\text { DE5 } \\
(\%)\end{array}$ & $\begin{array}{c}\text { DE8 } \\
(\%)\end{array}$ \\
\hline 1 & 97,3 & $120,1 a^{4}$ & 3,6 & 5,8 & 0,0 & $97,3 \mathrm{a}$ & $62,6 b$ & $40,8 b$ & $30,3 b$ \\
\hline 2 & 98,1 & $115,7 \mathrm{ab}$ & 4,0 & 4,7 & 1,4 & $96,7 \mathrm{a}$ & $65,0 \mathrm{~b}$ & $43,7 b$ & $33,1 b$ \\
\hline 3 & 97,3 & $110,7 b$ & 3,5 & 4,3 & 1,9 & $95,3 \mathrm{ab}$ & $62,8 b$ & $41,4 b$ & $31,2 b$ \\
\hline 4 & 95,5 & $102,8 \mathrm{c}$ & 3,6 & 2,6 & 1,9 & $93,5 \mathrm{ab}$ & $62,2 b$ & $41,3 b$ & $31,2 b$ \\
\hline 5 & 99,7 & $104,8 b$ & 3,8 & 2,1 & 3,2 & $96,5 \mathrm{a}$ & $66,3 \mathrm{ab}$ & $44,7 b$ & $34,2 b$ \\
\hline 6 & 99,5 & $99,6 \mathrm{~cd}$ & 4,3 & 2,7 & 11,2 & $88,3 b$ & $71,2 \mathrm{a}$ & $51,8 \mathrm{a}$ & $41,9 \mathrm{a}$ \\
\hline $\mathrm{EPM}^{5}$ & 1,43 & 2,95 & 0,20 & 0,84 & - & 1,43 & 1,14 & 1,13 & 1,00 \\
\hline
\end{tabular}

${ }_{1}^{1}$ ) Grão de sorgo seco e moído (2mm); 2) Grão de sorgo seco, moído (3mm), reidratado com aspersão de água sobre o material, que foi imediatamente ensilado por 30 dias; 3) Grão de sorgo seco, inteiro, reidratado por três dias em tubo PVC e, em seguida, moído a 5mm; 4) Grão de sorgo seco, inteiro, reidratado por três dias em tubo PVC com aplicação de ar comprimido e, em seguida, moído a $5 \mathrm{~mm}$; 5) Grão de sorgo seco, inteiro, reidratado por três dias em tubo PVC e, em seguida, moído a 5mm, e imediatamente ensilado por 30 dias; 6) Grão de sorgo seco, inteiro, reidratado por três dias em tubo PVC com aplicação de ar comprimido, moído a $5 \mathrm{~mm}$ e, imediatamente, ensilado por 30 dias;

${ }^{2} \mathrm{~A}$ = fração potencialmente degradável; $\mathrm{B}$ = fração potencialmente degradável sob ação da microbiota, se não houvesse tempo de colonização (LAG); c = taxa constante de degradação da fração potencialmente degradável por ação da microbiota; $\mathrm{S}$ = fração solúvel + partículas com tamanho reduzido que atravessam os poros do náilon; $\mathrm{B} 1=$ fração potencialmente degradável sob ação da microbiota (A-S); DE2, DE5 e DE8 = degradabilidades efetivas calculadas, considerando-se taxas de passagem no rúmen $(\mathrm{k} 1)$ de $2 ; 5$ e $8 \% / \mathrm{h}$, respectivamente $(\mathrm{DE}=\mathrm{S}+((\mathrm{B} 1 * \mathrm{c}) /(\mathrm{c}$ $+\mathrm{k} 1))$ );

${ }^{3}$ Não foi feita análise de variância. O dado apresentado refere-se ao valor médio de três réplicas;

${ }^{4}$ Letras distintas na mesma coluna indicam médias diferentes $(\mathrm{P}<0,05)$;

${ }^{5} \mathrm{EPM}=$ Erro padrão da média. 
No rúmen, a maior parte do amido é fácil e rapidamente fermentada pelos microrganismos amilolíticos, embora o grau com que isso ocorra dependa, principalmente, das propriedades físicas e químicas dos grânulos de amido. Sendo assim, grãos que tenham sofrido intenso processamento físico (triturado ou esmagado) e/ou químico apresentam maior digestão ruminal (Owens et al., 1986). O processamento utilizado no tratamento 6 (grãos reidratados com aplicação de ar comprimido e ensilados) destacou-se dos demais $(\mathrm{P}<0,05)$ em relação à $\mathrm{DE}$ do amido (Tab. 4). A DE do amido sob taxa de passagem ruminal de $2 \% / \mathrm{h}$ (DE2) observada no tratamento 6 foi semelhante $(\mathrm{P}>0,05)$ à estimada para os grãos submetidos ao tratamento 5, em que foram reidratados e ensilados, que, por sua vez, assemelhou-se $(\mathrm{P}>0,05)$ às DE2 obtidas para os demais tratamentos (Tab. 4). Ressalte-se que essa taxa de passagem ruminal de $2 \% / \mathrm{h}$ pode ser considerada característica de animais em mantença. Para níveis mais elevados de desempenho animal, normalmente, observam-se taxas de passagem ruminal entre 5 e $8 \% / \mathrm{h}$. Considerando essas taxas de passagem no rúmen, os valores de DE5 e DE8 do amido estimados para o tratamento 6 foram superiores $(\mathrm{P}<0,05)$ aos obtidos para os demais tratamentos (Tab. 4), indicando maior aplicabilidade desse processamento de grãos de sorgo para inclusão na dieta de animais de níveis intermediários a elevados de produção. Segundo Hale (1973), estudos histológicos com grãos de sorgo reconstituídos mostram desorganização da matriz de proteína do endosperma. Os métodos de processamento podem ter efeito marcante no rompimento da matriz proteica e facilitam o acesso das enzimas bacterianas e/ou enzimas do animal aos grânulos de amido.

A forma de reconstituição utilizada por Vieira (2011) foi semelhante à preconizada no tratamento 5 (Tab. 1), em que os grãos de sorgo reidratados foram, adicionalmente, moídos e ensilados. No entanto, no presente experimento, os processamentos utilizados não foram suficientes para alterar $(\mathrm{P}>0,05)$ as $\mathrm{DE}$, quando comparados com as observadas nos grãos minimamente processados por moagem $(2 \mathrm{~mm})$ do tratamento 1 (Tab. 1). Moron et al. (2000) observaram que a redução do tamanho da partícula promoveu incremento na DE do amido de grãos de milho e de sorgo, sem a necessidade de aplicação de calor com o objetivo de geleificar o amido. Esse aumento pode ser explicado pela separação dos grânulos de amido na matriz proteica, expondo-os ao ataque dos microrganismos do rúmen.

Sullins et al. (1971) estudaram quatro métodos de processamento de grãos de sorgo: moídos secos; moídos secos e reconstituídos; moídos secos, reconstituídos e moídos novamente; e reconstituídos inteiros e moídos. Análises microscópicas indicaram que a estrutura do endosperma dos grãos reconstituídos foi modificada, o que facilitou a liberação dos grânulos de amido e corpos de proteína, e representaram a alta proporção de pequenas partículas nos grãos moídos. Segundo os autores, a liberação de amido e proteína, combinada com a diminuição do tamanho das partículas, provavelmente explica o aumento da eficiência alimentar dos grãos reconstituídos. A provável causa das modificações é a hidrólise enzimática de proteínas, amido e outros hidratos de carbono que ocorrem decorrentes da alta umidade de armazenamento dos grãos, especialmente naqueles que não foram moídos antes da reconstituição.

\section{CONCLUSÕES}

O processamento de reidratação por três dias com aplicação de ar comprimido e ensilagem por trinta dias aumentou a degradabilidade efetiva da matéria seca e do amido dos grãos de sorgo, e sua utilização pode ser recomendada para animais em níveis intermediário e elevado de desempenho.

\section{AGRADECIMENTOS}

À Embrapa Gado de Leite, à Embrapa Milho e Sorgo, ao Conselho Nacional para o Desenvolvimento Científico e Tecnológico (CNPq), à Comissão de Aperfeiçoamento de Pessoal de Ensino Superior (CAPES) e à Fundação de Amparo à Pesquisa do Estado de Minas Gerais (FAPEMIG). 


\section{REFERÊNCIAS}

ANDRADE FILHO, R.; REIS, R.B.; PEREIRA, M.N.; ANTENOR, M. Degradabilidade ruminal in situ de grãos de milho maduros do tipo flint ou dentado, secos ou reconstituídos e ensilados. In: REUNIÃO ANUAL DA SOCIEDADE BRASILEIRA DE ZOOTECNIA, 47., 2010, Salvador. Anais... Viçosa: Sociedade Brasileira de Zootecnia, 2010.

BALOGUN, R.O.; ROWE, J.B.; BIRD, S.H. Fermentability and degradability of sorghum grain following soaking, aerobic or anaerobic treatment. Anim. Feed Sci. Technol., v.120, p.141-150, 2005.

FARIA Jr., W.G.; GONÇALVES, L.C.; TEIXEIRA, A.M.; CARVALHO, W.T.V. Grão de sorgo na alimentação de gado de leite. In: GONÇALVES, L.C.; BORGES, I.; FERREIRA, P.D.S.F. Alimentos para gado de leite. Belo Horizonte: FEPMVZ., 2009. p.282-304.

HALE, W.H. influence of processing on the utilization of grains (starch) by ruminants. $J$. Anim. Sci., v.37, n.4, p.1075-1080, 1973.

JOBIM, C.C.; BRANCO, A.B.; SANTOS, G.T. Silagem de grãos úmidos na Alimentação de bovinos leiteiros. In: SIMPÓSIO GOIANO SOBRE MANEJO E NUTRIÇÃO DE BOVINOS DE CORTE E LEITE, 5., Goiânia. Anais... Goiânia: UEM-Maringá, p.357-376, 2003.

LOPES, A.B.R.C.; BIAGGIONNI, M.A.M.; BERTO, D.A. et al. Método de reconstituição da umidade de grãos de milho e a composição química da massa ensilada. Biosci. J., v.21, p.95$101,2005$.

LOPES, F.C.F.; OLIVEIRA, J.S.; LANES, E.C.M. et al. Valor nutricional do triticale (X Triticosecale Wittimack) para uso como silagem na Zona da Mata de Minas Gerais. Arq. Bras. Med. Vet. Zootec., v.60, p.1484-1492, 2008.

MORON, I.R.; TEIXEIRA, J.C.; OLIVEIRA, A I.G. et al. Cinética da digestão ruminal do amido dos grãos de milho e sorgo submetidos a diferentes formas de processamento. Cienc. Agrotec., v.24, p.208-212, 2000.

NOCEK, J.E. In situ and other methods to estimate ruminal protein and energy digestibility: a review. J. Dairy Sci., v.71, p.2051-2069, 1988.
ØRSKOV, E.R.; McDONALD, I. The estimation of protein degradability in the rumen from incubation measurements weighted according to rate of passage. J. Agric. Sci., v.92, p.499-503, 1979.

OWENS, F.N.; ZINN, R.A.; KIM, Y.K. Limits to starch digestion in the ruminants small intestine. J. Anim. Sci., v.63, p.1634-1648, 1986.

PASSOS, L.P. Métodos analíticos e laboratoriais em fisiologia vegetal. Coronel Pacheco: Embrapa Gado de Leite,, 1996. 223p.

PEREIRA， M.L.R.; LINO, F.A.; MELO, AH.F. et al. Degradabilidade de grão reconstituído de milho e sorgo ensilados com diferentes granulometrias. In: XXI CONGRESSO BRASILEIRO DE ZOOTECNIA. INOVAÇÕES TECNOLÓGICAS E MERCADO CONSUMIDOR, 3., 2011. Maceió. Anais... Maceió: Universidade Federal de Alagoas, 2011.

SAMPAIO, I.B.M.; PIKE, D.J.; OWEN, E. Optimal design for studying dry matter degradation in the rumen. Arq. Bras. Med. Vet. Zootec., v.47, p.373-383, 1995.

STATISTICAL analisys sitem - SAS Institute Inc. $S A S^{\circledR}$ User's Guide: Statistics, Version 5 Edition. Cary, NC: SAS Institute Inc., 2002.

SILVA, J.S.; QUEIROZ, A.C. Análise de alimentos: métodos químicos e biológicos. 3.ed. Viçosa: UFV, 2002. 235p.

SULLINS, R.D.; ROONEY, L.W.; RIGGS, J.K. Physical changes in the kernel during reconstitution of sorghum grain. Cereal Chem., v.48, p.567-575, 1971.

THE NUTRIENT requirements of ruminant livestock - ARC. Suppl.1. London: CAB, 45p, 1984.

VAN SOEST, P.J.; ROBERTSON, J.B.; LEWIS, B.A. Methods for dietary fiber, neutral detergent, and nonstarch polysaccharides in relation to animal nutrition. J. Dairy Sci., v.74, p.35833597, 1991.

VIEIRA, A.R. Consumo e digestibilidade aparente dos nutrientes de dietas contendo sorgo em grão seco ou reidratado e ensilado para novilhos Nelore confinados. 2011. 68f. Dissertação (Mestrado em Zootecnia) - Escola de Veterinária, Universidade Federal de Minas Gerais, Belo Horizonte. 